\title{
Exploring Cultural Knowledge in EFL Teaching in an EAVSC*
}

\author{
Leijuan Hou \\ School of Humanities, Beijing University of Posts and Telecommunications, Beijing, China \\ Email: houleijuan@yahoo.cn \\ Zhihong $\mathrm{Lu}$ \\ School of Humanities, Beijing University of Posts and Telecommunications, Beijing, China \\ Email: zhihonglu2002@yahoo.com.cn
}

\begin{abstract}
Teaching cultural knowledge of the target language has been an ever-increasing focus in English as a foreign language (EFL) teaching in China during the last two decades. Apart from cultivating students' four basic skills, more and more attention has been paid to the enhancement of their cross-cultural competence. To achieve the goal, EFL teachers and researchers have been exploring both reasonable theoretical frameworks and effective practical measures. This paper aims to analyze a way of teaching cultural knowledge based on an English audio-video speaking course (EAVSC) at Beijing University of Posts and Telecommunications (BUPT). It presents the specific teaching modal from five aspects: the teaching material, the teaching context, the teaching principles and approach, students' speaking activities (both in-class and off-class speaking tasks), and the method to evaluate students' achievement. Through such a systematic organization and arrangement, this case study proves to be an effective way of cultural teaching.
\end{abstract}

Index Terms - teaching culture, cultural teaching model, cultural input

\section{INTRODUCTION}

Since the 1980s, 'culture' has raised a growing attention in foreign language teaching (FLT) and learning in China. The teaching goals have developed from 'linguistic ability' to 'communicative ability', and recently to 'intercultural communication competence' (Gao, 2002). Consequently, more and more studies have been conducted from the perspective of culture. These studies can be roughly categorized into three types: the teaching of culture in FLT; the cultivation of learners' cross-cultural competence; the influence of learning culture on FLT (Xu, 2004). Theoretically, culture is often regarded as a part of one's communicative ability, which is often termed as cross-cultural ability; in practice, the common methods suggested and adopted is to 'input' the teaching of culture in language teaching. Hence studies concerning 'cultural input' or other concepts alike sprang up (Lin, 1996; Han, 2002; Li, 2005; Liu, 2009).

Despite the above number of studies, there is still a long way to go to into the very core of teaching cultural knowledge. Although many scholars illustrated the importance of teaching culture in FLT, and provided some suggestions as to how to do it in practice, their implications seem somewhat general and few empirical cases are available for analysis and reference. This article, therefore, presents a case study of teaching culture based on an EFL audio-video speaking class at BUPT. By describing and explaining the operational links during the teaching procedures, it is expected that this study can shed some light on further exploration of cultural teaching.

\section{LITERATURE REVIEW}

Before approaching the question of 'cultural teaching', it is necessary to review some basic concepts related to 'culture'.

\section{A. The Nature of Culture}

Language and culture are intimately related. Language is both the carrier and main manifestation of culture. Scholars have provided a framework to identify the nature of culture, be it native culture or target language culture.

In Kohls' eyes, culture is an integrated system of learned behavior patterns that are characteristic of the members of any given society. It refers to the total way of life of particular groups of people. It includes everything that a group of people thinks, says, does and makes - its systems of attitudes and feelings. Culture is learned and transmitted from one generation to the next (Kohls, 1996).

\footnotetext{
* This study is a part of the Beijing city-level research project, "Research on the Teaching Model in English Audio-video Speaking Class (EAVSC) in CALL Environments" (2008-2010), supported by Beijing city government. During the process of paper composition and revision, the authors received great help from the Dartmouth-BUPT "Video Interaction-Based Education (VIBE) Language Exchange" Program.
} 
For Goodenough, "culture...consists of standards for deciding what is, standards for deciding what can be, standards for deciding how one feels about it, standards for deciding what to do about it, and standards for deciding how to go about doing it "(1963: pp. 258-259).

According to Straub, what educators should always have in mind when teaching culture is the need to raise their students' awareness of their own culture, to provide them with some kind of meta-language in order to discuss culture, and 'to cultivate a degree of intellectual objectivity essential in cross-cultural analyses' (1999: p. 5).

\section{B. Language Teaching and Cultural Teaching}

Scholars only began to delve into the dynamics of culture and its vital contribution to 'successful' language learning in the 1980s (Byram, Morgan et al., 1994). Culture has, either implicitly or explicitly, been taught in the foreign language classroom since then. Researchers and teachers endeavored to arouse students' cultural awareness and develop their intercultural competence through incorporation of culture in language teaching.

One frequently adopted framework is the 'language input model', a theory which posits that learners' cultural competence can be fostered by such methods as: annotation, incorporation, practical activities, comparison, and lecturing (Shu, 1996). Similar studies were conducted consecutively (Lin, 1996; Han, 2002; Li, 2005; Liu, 2009).

Combining cognitive linguistics and sociolinguistics, scholars proposed a cognitive-cultural model for teaching culture. Cognitive models, as the term suggests, represent a cognitive, basically psychological, view of the stored knowledge concerning a certain field; they depend on the culture in which a person grows up and lives, or the so-called cultural models. Cultural models can be seen as cognitive models that are shared by people belonging to a social group or subgroup (Ungerer \& Schmid, 2001). One's language acquisition process cannot be isolated to the cultural knowledge of the target language. Culture in language learning is also an essential part of knowledge that should be included along with rather than an extended skill to the teaching of listening, speaking, reading, and writing. Therefore, the authors in this article think that teaching culture should not be treated as an independent unit and cannot be fully infiltrated into students' knowledge systems simply by some external, discrete and deliberate practice of 'inputting' combined. Culture is more an internalized entity, which calls for an implicit, systematic and periodical internalizing permeating-oriented teaching process. This study is a tentative attempt at exploring the cultural knowledge in EFL in an EAVSC guided by this teaching ideology.

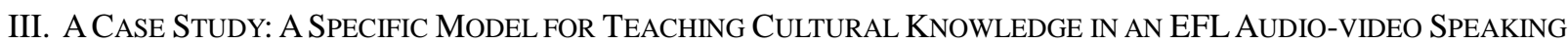 CLASS AT BUPT}

In this section, the authors will elucidate the model for teaching culture involved in the case study. Viewing the model as a systematic infiltration process, the authors will expound it from five dimensions, namely, the teaching material, the teaching environment, the teaching principles and teaching approach, in-class activities and outside class assignments, and the evaluation method.

\section{A. The Teaching Material}

The course set at BUPT is called 'Situational English', which is a relatively speaking more advanced speaking course with those students who scored high in $\mathrm{CET}^{1}-4$ as the teaching objects. The teaching objectives of the course conformed to the intermediate and higher requirements stated in College English Curriculum Requirements (Department of Higher Education, 2007). The teaching material for the course is 'Learning English through Culture: Viewing, listening, speaking', which was published by Foreign Language Teaching and Research Press. This book was co-written by the course-instructor, the second author, during her three years' life experience in America, a time when all the scenes in the textbook were taped by the second author.

The focus of the book is learning English through culture. It provides a considerable amount of cultural knowledge about both the target language and the students' mother tongue. Topics like holidays, food, entertainment, libraries and so forth were covered in the book, introduced in the form of audio clips or videos. All the videos of cultural background information and situational dialogues in each unit were based on authentic scenes in America, ranging from campus life to larger social activities. Since the course-instructor was totally involved in the photographing process, she was able to explain every location in each video at length to the students in class. In addition, she could tell them some additional information.

To summarize, as the author of the textbook, the course-instructor is able to manage the teaching links methodically with ease. The teaching content is not confined to the textbook only; instead, as an experienced teacher with bountiful western and eastern cultural knowledge, the she can supplement any cultural tips when necessary. This greatly aroused students' interests and motivated them to learn more, which is an essential prerequisite for successful teaching.

\section{B. The Teaching Environment}

\footnotetext{
${ }^{1}$ CET is the abbreviated form of "College English Test". The national College English Test Band Four CET-4 in China aims to evaluate non-English majors' comprehensive language proficiency. Apart from CET-4, there is also CET-6, which is widely used to evaluate above-average students' language proficiency. More than half of the students in this study, except for the Japanese majors, had passed CET-6 before taking the course. SET is the abbreviated form of "Spoken English Test", which is a portion of CET.
} 
The macro teaching environment can be described as a computer-assisted language learning (CALL) environment. The class was conducted in a language lab, which is equipped with a digital network operating system (WE-LL6000). Each computer is connected with one another through this system and under the manipulation of the teacher's computer. Therefore, the teacher and the students were able to communicate with one another via the network. When the teacher wants to show something to the whole class, she can use the headphone and a control screen on the teacher's panel; when she wants to let the students perform tasks, the panel is switched to a mode in which students are divided into different groups either randomly, or according to set rules. This environment guarantees that each student is equipped with an equal opportunity: a condition which cannot be fully satisfied in traditional classrooms. The specific WELL6000 operating system makes it possible for students to freely exchange ideas with different group members in different tasks without changing their seats. In addition, the teacher can join students' discussion either as either participant or knowledge provider. Therefore, this learner-friendly teaching environment creates a good communication platform between the teacher and students, which ensures an effective external support for further teaching activities.

\section{The Teaching Principles and Teaching Approach}

This course is a "student-centered" audio-video speaking class, which is theoretically based on Bachman's theory of communicative language ability (CLA) and hence adopts the communicative language teaching method and interactive teaching patterns. CLA consists of three parts: language competence, strategic competence and psycho-physiological mechanisms. In Bachman's eyes, "language competence comprises essentially a set of specific knowledge components that are utilized in communication via language" (Bachman, 1990, p. 84). The interactions of these components of CLA with the language use context and language user's knowledge structures are illustrated in the following two figures.

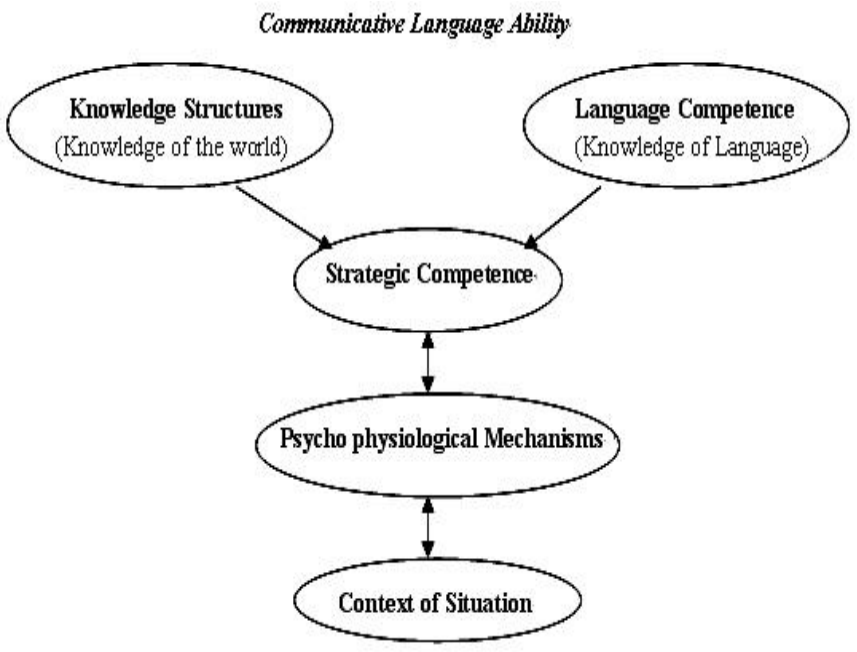

Figure 1. Components of communicative language ability in communicative language use (Bachman, 1990, p. 85)

Communicative language ability

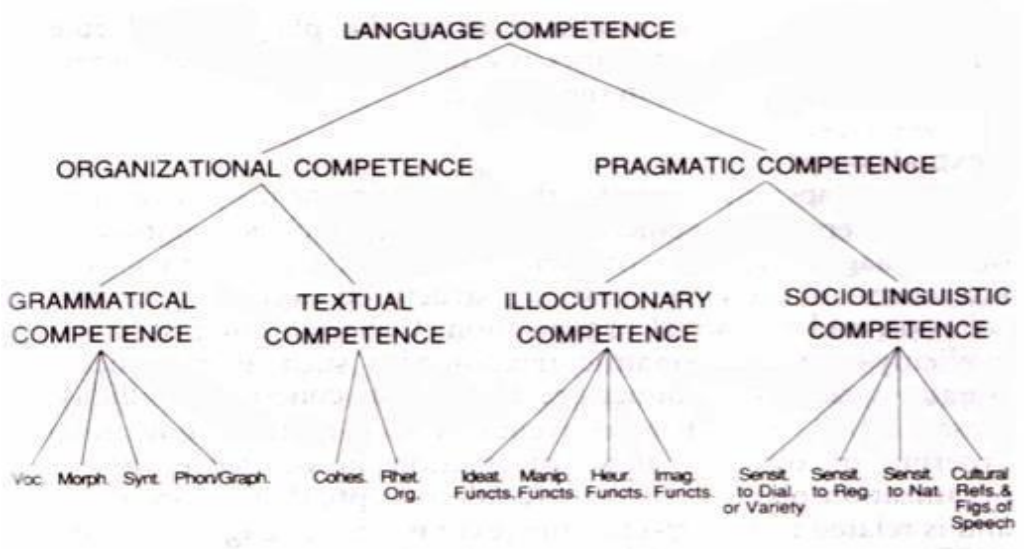

Figure 2. Components of language competence (Bachman, 1990, p. 87)

Apart from language competence, strategic competence, psycho-physiological mechanisms and context of situation, one's 'knowledge structures' - knowledge of the world, also plays a decisive role in constituting one's communicative 
ability. For a long time, the main purpose of teaching and learning English in China is to develop students' ability to use the target language as a tool under international contexts. It goes without saying that language is primarily used for interpersonal communication. However, at a higher level, language remains a system of signs unless it is endowed with certain content. In FLT classrooms, the teacher should be clear that in order to enable students to communicate in the target language in the full sense, it is indispensable to equip them with sufficient cultural knowledge in various areas. Only by doing this can students be both communicatively competent and culturally competent.

To achieve these two goals, the course-instructor taught the class in two stages. First, she showed a video about the topic of the class, as a lead-in. After that, the students were asked to finish tasks concerning the specific cultural topic introduced, either through working in pairs, or group discussion. The textbook was available for students to look up useful words and expressions. Occasionally, the teacher arranged rounds of debates over controversial issues, such as, 'Do you think one day the e-book will eventually replace traditional books?' or 'Shall western festivals be encouraged in China?' Through working in pairs, discussion or debate, students are expected to exchange opinions and deepen their cognition of certain topics, so that their knowledge of the world can be enriched.

Remarkably, the course-instructor not only aroused students' cultural awareness about the target language, but more importantly, she emphasized the importance of knowing about our own country. For example, when telling students about cuisine in the western world, she also let the whole class review the eight styles of cooking in China; when presenting traditions and customs from English-speaking countries, she also gave chances for students from different nationalities to introduce their own customs; when discussing art forms, she invited students to share their experience and knowledge with their classmates. After that, the teacher gave feedback on their input. This way, the interactions between teacher and students, and between the students in the class, were realized effectively. Finally, students were asked to summarize their attitudes or opinions over the given topic in one minute. In this section, they could express their original viewpoint, or add anything he/she deemed important or interesting that he acquired during the whole class. In this sense, students progressed in terms of communicative competence as well as intercultural competence.

\section{In-class Activities and Outside Class Assignments}

Two main in-class activities are pair-work dialogues and group discussions. Pair-work dialogues usually last for about five minutes, carried out between desk mates. Group discussions are about six minutes, conducted among three or four persons each time. They discuss certain cultural topics or social phenomena that they are interested in. Language accuracy is emphasized less than fluency, because the main purpose is to enhance students' communicative ability. Therefore, the students were trained to employ useful communicative strategies to enhance the interaction. In this learner-centered class, students actively acquired knowledge through the co-operation of the class as a whole. Apart from pair-work dialogues and group discussions, debates are also organized over some controversial issues. This is an effective means for training students' logical ability as well as the ability to see things from two angles. For instance, in a debate over the same topic, students are expected to take opposite standpoints on different rounds. Sometimes roleplaying is also included on appropriate occasions. For example, when enjoying the world-famous movie-Roman Holiday, the teacher asked volunteers to imitate one dialogue between the princess and the reporter. All the students were impressed by their classmates' excellent performance, and everyone enjoyed this course a great deal.

At the end of each class, the teacher tells the class what they are going to discuss next time, and asks them to prepare enough information beforehand. In this way, even if students know little about the given topic originally, various resources are available to help them. This procedure, which is regarded as a means of autonomous learning, makes it possible for further effective development of working in pairs and group discussion. In addition, in the classroom, the students are also encouraged to bring up any topic that they are interested in. They can take full advantage of the platform created by the course-instructor. In addition, there is a CD-ROM of the teaching material available to everyone, so students can spend their spare time studying the content that could not be covered in class due to the time limit; or go over those cultural tips and videos covered in class.

\section{E. The Evaluation Method}

For the evaluation of this course, three parts constitute the students' final score. The first part - the final examination, includes a one-minute personal statement on a given topic, five-minutes of working in pairs on some authentic topics, and a three- or four-person group discussion in which everyone chairs a topic for about two minutes. The one-minute personal statement tests students' logical ability and organizational competence to express his/her opinion or attitude towards a given topic, and to use two or three reasons to support it. The five-minutes of working in pairs and group discussion takes similar forms that students have become accustomed to after one semester's practice. The topics in pair work are based on students' real-life experiences, with the purpose of testing their communicative ability; the topics in group discussion are chosen by students themselves from the textbook in each unit, which serve as an parameter for checking whether students' cultural perspective have been widened and their logical ability has been distinctively improved. All three parts in the final examination were recorded with the help of the WE-LL6000 system, in order to assess students' performance, and for further research purposes.

The second part focuses on students' behavior in class, and the third part is more focused on students' effort on cultural acquisition. About three weeks before the final examination, all the students were asked to fulfill a task either on their own or through cooperation with partners. They can choose one cultural aspect that interests them, and give a 
presentation on the topic to the whole class. The contents and forms are flexible as long as one can bring it into full play. For example, one student researched the origin and development of Chinese opera and combined it with its cartoon versions, adding fresh elements to the seemingly 'abstruse' art form; others chose a certain film star or famous singer and gave a comprehensive introduction to his/her career and representative works; some boys showed their enthusiasm for jazz, rock and roll; a few girls discussed their favorite novelists. Through this format, everyone exhibited their understanding of certain cultural phenomena of their own country, as well as their knowledge of others'. Hence, it is a good means of assessing the cultural teaching and learning in this course.

\section{CONCLUSION AND IMPLICATIONS}

After a detailed illustration of the cultural teaching model in this case study, this specific way of teaching culture proves to be valid. Taking into account the teaching materials, the teaching environment, the teaching principle $\&$ teaching approach, in class activities as well as outside class activities, and the evaluation form, a well-organized cultural system has been built. Culture is not an independent and external factor; instead, it should be grounded into the learners' mind. Only by perceiving authentic target cultural knots and upgrading one's cognitive understanding towards them, can students grasp the essence of the target language culture inherently. Another important point is that, while acquiring western cultural knowledge, Chinese students should be aware that one should not forget his/her own culture. This is also in accordance with one important FLT principle, which is to raise the students' awareness of patriotism. We hope that this study can serve as a reference for English language teachers and scholars. In the meantime, further theoretical investigations are needed to improve this model.

\section{REFERENCES}

[1] Bachman, Lyle F. (1990). Fundamental considerations in language testing. Oxford: Oxford University Press, 84-85.

[2] Byram, M., Morgan, C. and Colleagues. (1994). Teaching and learning language and culture. Great Britain: WBC.

[3] Gao, Yihong. (2002). Developing intercultural communication competence: Going across and beyond, Foreign Languages and Their Teaching. (10): 27-31

[4] Goodenough, W. H. (1963). Cooperation in change. New York: Russell Sage Foundation.

[5] Han, Xiaoling. (2002). On embedding language teaching in culture teaching, Foreign Languages and Their Teaching. (12): 2956

[6] Kohls L. R, (1996). Survival kit for overseas living. Maine: Intercultural Press, Inc. 1-23.

[7] Li, Chuan. (2005). The research on the culture ducting problem of the language teaching, Education Exploration. (8): 63-64

[8] Lin, Ruchang. (1996). Three layers of foreign language teaching and cultural input. Foreign Language World. (4): 1-6

[9] Liu, Liqiu. (2009). Incorporation of cross-cultural teaching in English teaching. Journal of Wuhan Institute of Shipbuilding Technology. (2): 23-32

[10] Lu, Zhihong, \& Steele, Loren. (2006). Learning English through culture: viewing, listening, speaking. Beijing: Foreign Language Teaching and Research Press.

[11] Ministry of Education, Department of Higher Education. (2007). College English curriculum requirements. Shanghai: Shanghai Foreign Language Education Press.

[12] Shu, Dingfang. (1996). On the relationship of language and culture and the issue of cultural input in the basic English teaching. Foreign Language World. (1): 11-17

[13] Straub, H. (1999). Designing a cross-cultural course. English Forum, vol. 37: 3, July-September.

[14] Ungerer F, \& Schmid H J. (2001). An introduction to cognitive linguistics. Beijing: Foreign Language Teaching and Research Press, 51

[15] Xu, Jian. (2004). Cultural perspective in researches on foreign language teaching and learning. Journal of Educational Science of Hunan Normal University. (4): 115-117

Leijuan Hou was born in Zhangiakou, China in 1986. She is pursuing her M.A. degree in Applied Linguistics at Beijing University of Posts and Telecommunications, China, registered in 2008.

She is currently an M.A. student in the School of Humanities, Beijing University of Posts and Telecommunications, Beijing, China. Her research interests include applied linguistics, computer-assisted language learning, sociolinguistics and language testing.

Zhihong Lu was born in Urumchi, China in 1963. She received her B. A. degree of English Education from Capital Normal University, China in 1985. She attended the Graduate Training Program at Beijing Foreign Studies University during 1993-1994, specializing in applied linguistics.

She is currently a professor and supervisor of master students in the School of Humanities, Beijing University of Posts and Telecommunications, Beijing, China. Her research interests include applied linguistics, computer-assisted language learning, sociolinguistics and language testing. 